\title{
Publisher Correction: Ancestral-sequence reconstruction unveils the structural basis of function in mammalian FMOs
}

Callum R. Nicoll D, Gautier Bailleul, Filippo Fiorentini, María Laura Mascotti (D), Marco W. Fraaije and Andrea Mattevi (D) Correction to: Nature Structural and Molecular Biology https://doi.org/10.1038/s41594-019-0347-2, published online 23 December 2019. In the print and PDF versions of this article initially published, panel e was missing from Fig. 6 . The error has been corrected in the PDF version of the article.

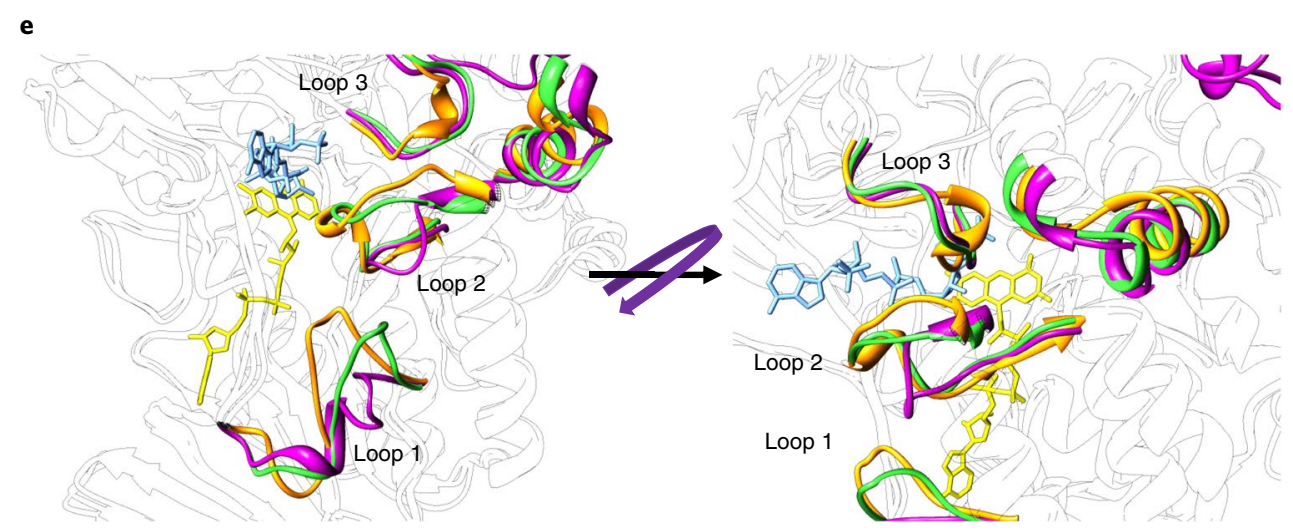

Fig. 6e

Published online: 21 January 2020

https://doi.org/10.1038/s41594-020-0378-8

๑) The Author(s), under exclusive licence to Springer Nature America, Inc. 2020

\section{Publisher Correction: Asymmetric opening of HIV-1 Env bound to CD4 and a coreceptor-mimicking antibody}

Zhi Yang, Haoqing Wang, Albert Z. Liu (D), Harry B. Gristick and Pamela J. Bjorkman (D)

Correction to: Nature Structural and Molecular Biology https://doi.org/10.1038/s41594-019-0344-5, published online 2 December 2019.

In the version of this article initially published, in Fig. $6 \mathrm{~b}$, top left panel, the $\beta$-sheet was labeled as a "Three-stranded bridging sheet."

The correct label is "Four-stranded bridging sheet." The error has been corrected in the HTML and PDF versions of the article.

Published online: 21 January 2020

https://doi.org/10.1038/s41594-020-0381-0

(c) The Author(s), under exclusive licence to Springer Nature America, Inc. 2020 